\title{
A Tiny Language: Implementing a 'Real Character'
}

\author{
lan Maun \\ University of Exeter, United Kingdom
}

\begin{abstract}
This paper outlines the research thus far undertaken on a 'Real Character' (RC) for the digital age, i.e., a pasigraphy (a read-only form of writing) which may be understood by speakers of mutually unintelligible languages. Using Basic English (Ogden 1930, inter al.) as a lexicon, symbols drawn from the work of Haag (1902, 1935) and other symbols, a 'Tiny Language' is developed, with a minimal lexicon and few rules. Additional lexical items are created by combining fundamental RC characters. Learning-principles and
\end{abstract}

\footnotetext{
Ian Maun

Honorary Research Fellow at Graduate School of Education, University of Exeter, United Kingdom

Email: I.C.Maun@ex.ac.uk
}

Received 16 June, 2018; Revised 7 August, 2018; Accepted 15 August, 2018

Copyright (C 2018 Language Research Institute, Sejong University

Journal of Universal Language is an Open Access Journal. All articles are distributed online under the terms of the Creative Commons Attribution Non-Commercial License (http://creativecommons.org/licenses/by-nc/3.0) which permits unrestricted non-commercial use, distribution, and reproduction in any medium, provided the original work is properly cited. 
exercises are provided. The question of the further development of $\mathrm{RC}$ is raised, together with the possibility of its becoming a handwritten script as well as digital character.

Keywords: Real Character, Tiny Language, adverbial adjuncts, Haag symbols, script-form

\section{Introduction}

\section{1. 'Real Character': A Summary}

This is the fifth in a series of papers (following Maun 2013, 2015, $2016,2017)$ which attempts to outline the possible development of an international digital means of communication. Based on the ideas of the $17^{\text {th }}$ - and $18^{\text {th }}$-century 'language projectors' (e.g., Wilkins, Dalgarno and Leibniz), the 'Real Character' proposed here (hereafter, $\mathrm{RC}$ ) is a pasigraphy, a read-only system of characters, some iconic, some symbolic, which may be read by a reader who does not speak or read the language of the writer. While early inventors of such systems imagined a 'universal language' which could be written for anyone and read by anyone, Maun (2017) shows that a symbolic language can be constructed but, because of the way in which different cultures and languages divide up 'reality', it would be more effective to focus or tune this symbolic language to that of the intended recipient.

In brief, the elements accumulated thus far include:

- A small lexicon of c. 850 words, using Ogden's system of Basic English (Ogden 1930, 1944; Ogden, ed., 1940) as its foundation, as this list fits in with words or concepts found 
in many languages (Swadesh 1950, 1971; Goddard 1993, 2010). Additional lexical items are formed by using the 850 words in combination. Ogden's Basic English is hereafter referred to as 'BE'.

- $\quad$ The principle that visible objects will be represented by icons (in the Peircean sense) and abstract concepts by symbols (again, in the Peircean sense)

- A set of formational parameters for the creation of characters, using straight lines (vertical, horizontal and oblique) and curved lines to represent objects which contain such features. For more metaphorical uses, straight lines are used for 'hard' concepts (e.g., firmness, masculinity, cruelty...) and curved lines for 'soft' concepts (e.g., softness, femininity, kindness...) (Dondis 1973, Frutiger 1989).

- $\quad$ Symbols derived from the work of $\operatorname{Karl} \operatorname{Haag}(1902,1935)$, consisting principally of lines, dots and arrows, which act as semantic primes and which are based on Haag's premise that language is based on space and the human body's relation to it. Haag extends his symbols from space into various fields, e.g., Time, such that the basic spatial symbol meaning in front of will mean before as a preposition or adverb, and precedence as a noun (Maun 2016). Haag's 'force level' markers will also be used, e.g., his Level III (Causation) marker, now represented as '['.

- A visible syntactic frame, consisting of a T-shaped bar, on 
which the predicator of a sentence is placed on the top, and the subject and complement in the angles. Thus the elements Subject-Verb-Complement (S-V-C) are placed thus:

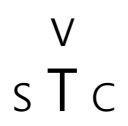

Both Subject and Complement will contain elements such as articles, demonstratives and adjectives. Relative clauses are shown as sub-sentences linked to their referent. Verbs may contain a tense-marker (see Sections 2.4, 2.6 and 3.2), but adverbial modifications are shown outside the main T-bar structure (see Sections 2.8-2.11).

If an indirect object is to be shown, the $\mathrm{T}$ becomes an Ishape, with the indirect object at the bottom (Maun 2013, 2016). The symbols are read, not in any linear order, but in the natural order of the recipient's own language, e.g., for Japanese, S-C-V.

- A Real Character Device (RCD), being a digital device which will convert language into glyphs consisting of characters (icons, symbols). Just as technology is used to convert an SMS message originally written on an i-phone in Pinyin (Romanized Chinese) into genuine Chinese characters, so similar technology will be used on the RCD. The language of the recipient will be set, and the device will recognise words written in the source language and convert them into the appropriate glyphs for the language of the 
target-speaker. The complex glyphs will be formed from a universal set of elements.

A word in a given target language will be given an ASCIIcode-like index, and when the source language is typed in, the given code number will produce the 'translation' in RC on the screen, the word consisting of elements taken from the universal 'set'. Today, for Chinese SMS massages, alternative characters are offered to the sender for words such as 'ma', which has different meanings (and therefore different characters) according to the tone on which it is sounded. Similarly, in the future, alternatives will be offered by the RCD, e.g., if the target-reader is German, when an English-speaking writer types in 'go', the RCD will offer him/her the choice of glyphs for 'go on foot', 'go by car/vehicle', 'go by plane', 'go by ship', etc, as there is no all-encompassing verb in German where English may use the simple 'go' (see Maun 2017). The writer selects the appropriate glyph.

The message is sent and is then presented to the reader using Rapid Serial Visual Presentation (RSVP) (Öquist \& Goldstein 2002) in the natural order of his/her language. Additional support for the reader is supplied by an accessible underlying layer of information including semantic primes (Maun 2015). Using this would be like flipping between windows in Microsoft Windows ${ }^{\mathrm{TM}}$.

The present paper is divided into two parts. Part A defines the aims of the article and sets out various principles that will govern the syntax and arrangement of a Tiny Language. There will be discussion of principles of syntax and semantics from natural 
90 A Tiny Language: Implementing a 'Real Character'

languages which are used to justify their incorporation into RC. Part B introduces the icons and symbols that will be used and which will combine to produce more complex glyphs. Aspects of the aesthetics of a TL are considered, as well as the possible use of RC as a written, as well as a digital, script.

\section{Part $A$}

\subsection{A Tiny Language}

The aim of the present paper is to take a Tiny Language, i.e., a very limited amount of lexical material from BE, and a restricted number of rules, and to investigate how such a language might be represented in RC and how this small body might best be visually represented. The term 'Tiny Language' (hereafter, TL) is taken from computing, in which small amounts of data and rules are combined.

The syntactic arrangements which will be used to represent the TL will be discussed, as more than the simple Subject-Verb-Complement structure will be required.

The question of cognitive dissonance and the role of aesthetics in the creation of RC script will also be addressed, using historical examples for guidance. It may then be possible to signpost ways forward for further development.

\subsection{Beginning from Basics: The 'Telescope Principle'}

In both creating characters and structures, and in imparting them to readers, we work on 'the Telescope Principle', that is to say, one 
begins with a very small amount of material and then one gradually increases it, so that the overall picture gradually becomes larger, much like looking through a telescope. This also applies to the learning of the characters - a little at a time.

\subsection{Defining the Tiny Language}

In order to test the proposed framework, we shall need to define the limited vocabulary that will constitute the TL. Once this lexicon has been established, it will become possible to define ways in which elements may be combined and the ways in which these lexical items may be represented in what we may term $R C$ script.

If we confine ourselves to $\mathrm{BE}$ as it stands, it is not immediately possible to create even a simple sentence such as $A$ man leaves a house, as $\mathrm{BE}$ contains no verb leave. This is because leave is considered to be a synonym of two other combined BE elements, go and from. Similarly, there is no verb arrive, since this can be created from come and to. We shall therefore choose the first part of the lexicon from words which occur in BE. The second part of the lexicon will consist of words such as leave and arrive which can only be formed using other, more basic BE elements, or for which a Haag symbol already exists.

Such an approach will of necessity produce very short (and, frankly, not very useful) sentences in the early stages of the development of the TL but greater complexity and applicability will gradually develop.

\subsection{Speech Acts and Tense}

- In the TL, it will be necessary to make statements, ask questions, make exclamations, give commands, express possibility and 
92 A Tiny Language: Implementing a 'Real Character'

other modalities, and to combine these elements.

- It will be necessary to talk about the past, the present and the future in any of these speech acts.

- It will be necessary to negate verbs and adverbs, e.g., 'did not go', 'not tomorrow'.

\subsection{Speech Act Markers}

It was suggested in Maun (2013) that any distinctive Speech Act (SA) marker such as 'Question' (?), 'Exclamation' (!) or 'Command' (!!) should be placed at the junction of the two strokes of the T-bar. It seems logical, however, to de-clutter the T-bar and to use available space to place any necessary Speech Act marker. Therefore, rather, than place the SA marker within the T-bar, as previously suggested, it would be preferable to place it at the very top of the glyph, thus announcing to the reader the nature of the speech act about to be encountered (cf. Spanish punctuation, which requires an inverted question mark before a question and an inverted exclamation mark before an exclamation or command). The SA marker is thus the first element encountered in this new arrangement and presented using RSVP. It is an important rule of RC that, whatever the reader's native direction of reading, RC glyphs are always read from top to bottom (see Maun 2015).

Modalities such as 'Possibility', 'Impossibility' and 'Probability/Likelihood' may be included in the gamut of SA markers. It thus becomes possible to mark sentences with initial parts such as 'It is possible that...', 'Is it possible that...?', 'It is not possible that...' and 'Is it likely that...?'. Moreover, introductory phrases such as 'I think 
that...', 'I believe that...', 'I hope that...' can be treated in the same way, rather than as the main clause of a complex sentence. With such a device clearly marked at the top of the glyph, the reader immediately knows 'where the sentence is going'.

\subsection{Tense}

To add tense, it is necessary to add a tense marker, except for the present which remains unmarked as the 'default' tense. In Haag's (1902) system, 'past' is regarded as a shift of 'in front of' in the Spatial category into the Temporal category. Similarly, 'future' is regarded as a shift of 'behind' into the Temporal category. These markers will be used to define tense and placed in the appropriate position adjacent to the verb, as defined below (Section 3.2).

It must be recognised that not all languages mark tense in the way that European languages do, e.g., Mandarin (Crystal 1987) and Pirahã (Everitt 2012), while others define time periods and distance from the speaker differently, e.g., Matses (Deutscher 2010). This language also requires the truth of a statement to be defined, along with tense. These are complex issues which cannot be dealt with at this stage of the development of RC. As shown in Maun (2017), the use or otherwise of such markers will be dependent in part on the language of the reader. While RC's elements will probably be universal, their combination and use will be pragmatic. One size will definitely not fit all.

\subsection{Syntax in RC: Place-Value as a Principle}

Kroskrity (2015) points out that in Arizona Tewa, an indigenous American language of the Kiowa-Tanoan family, the position of a 
syntactic element in a sentence in part gives information on that element's function. Thus a simple S-V-C sentence can consist of the roles AGENT-PATIENT-VERB, but the PATIENT can be incorporated within the VERB. Any sentence containing this construction guarantees that the element within the verb is the PATIENT. However, a sentence can also consist of an unmarked noun, followed by a noun marked as OBLIQUE, followed by a second noun marked as OBLIQUE, then the VERB marked as INVERSE. In this case the first noun is taken as the PATIENT, the second as the AGENT, the third as INSTRUMENT, with the verb form indicating that the sentence is to be taken as passive in sense. A slightly simplified version of Kroskrity's example is as follows (OBL = OBLIQUE; $\mathrm{INV}=$ INVERSE; PST = PAST TENSE):

Ne'i waayhe'isen-di/ he-i athu-di oo-hey-an

This horse that man-OBL/ that car-OBL/ INV-kill-PST

'This horse was killed by that man with that car.'

While two nouns are marked as OBLIQUE, it is the position of 'that car', occurring after 'that man', which indicates that it is to be interpreted as an INSTRUMENT. Place-value determines function.

In a language closer to home, namely English, function may also be marked by position. If a verb requires both a direct and an indirect object in which the preposition 'to' is suppressed, the indirect object must precede the direct object. Thus:

- I've given the man the book.

- I'll send my wife the letters.

- I offered the conductor my ticket. 
This adds support to the incorporation of place-value as a guiding principle in RC. In standard English, this ordering is also required with pronouns. Thus, substituting pronouns for the nouns in the above sentences, we get:

- I've given him it.

- I'll send her them.

- I offered him it.

As indicated in Maun (2017) some dialects of English (e.g., Northern) require a reversal of this order. It should be noted, however, that the reversal is quite systematic. In these dialects, the place-value is quite consistent, i.e., the pronominal direct object precedes the pronominal indirect object: 'I've given it him'. Place-value holds good.

We can thus use place value to indicate peripheral functionality, just as we have done for S-V-C on the T-bar

\subsection{Adverbial Adjuncts: Time, Manner, Place}

Traditionally, adverbs have been divided into those of Time, Manner and Place. This categorisation is somewhat simplistic but will suffice as a temporary device during the development of RC. That this tripartite division has some reality is shown by the grammar of German, which requires that, if there is more than one adverb or adverbial phrase, then the order must be Time (T) - Manner (M) Place (P), e.g., Er (S) trank (V) dann (T) schnell (M) etwas Wasser (C) in der Küche $(\mathrm{P})=$ 'He then quickly drank some water in the kitchen.' No other ordering is permissible with the present syntactic construction. (If the sentence commences with Dann (= 'then'), 
however, this will have syntactic consequences, causing inversion of subject and verb [since the verb must remain as the second syntactic element] and separation from the other adverbial elements: Dann trank er schnell etwas Wasser in der Küche. Note that the remaining adverbials, $\mathrm{M}$ and $\mathrm{P}$, retain their required order.)

Because adverbials are not central to a message, unlike S-V-C, it seems logical that they should be placed outside the T-bar. By placing them thus, their lack of centrality is emphasised and the Tbar itself remains uncluttered. It is therefore proposed that the adverbials should be marked using brace symbols $(\{\}$,$) , with Time at$ the top (as it is closely associated with the tense of the verb) and Place at the bottom. Manner will be placed on the right of the glyph. In all cases, the point of the brace symbol will face the adverbial adjunct.

Figure 1. Adverbial Positions

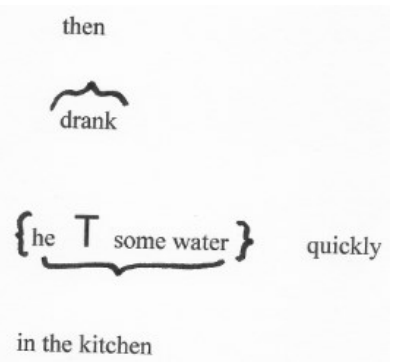

As with S-V-C on the T-bar, the function of an adverbial is determined by place-value in the 'orbit' around it, i.e., if an adverbial is at the top, it indicates 'time', if on the right, it indicates 'manner', and if at the bottom, 'place'.

Croft \& Cruse (2004: 228) draw some complex distinctions 
between various types of sentences containing adverbial modification:

A) Oblique Adjunct Phrase: John ate the tart with a fork and spoon.

B) Prepositional Complement Phrase: John ate the tart in the refrigerator.

C) Circumstantial Phrase: John ate the tart in the living room.

D) Nominal Prepositional Phrase Marker: the tart on the table.

While these uses show real and important distinctions, only Type A, which falls under Instrumentality (see below, Section 2.9), and Type C, under Place, are genuine adverbial uses. Types B and D are reduced relative clauses - B: '...which was in the refrigerator'; D: 'the tart which is/was on the table'. Ways of dealing with Types B and $\mathrm{D}$ will be shown in Section 2.12 .

\subsection{Instrumentality}

Traditional grammar would treat the two sentences He hit the nail with a hammer and He hit the nail repeatedly in a similar manner, regarding 'with a hammer' and 'repeatedly' simply as adverbs or adverbial phrases. The first, however, belongs to a category that we might call 'instrumentality', in which phrases are often introduced by 'with', 'using', 'by' or an adverb terminating in '-ly'. Thus:

- Anna tied the parcel up with string.

- Bernie shot the bandit with his pistol.

- Diana opened the Yale lock using her credit card.

- Peter obtained admittance by pressing the door-bell. 
- We must examine this scientifically (i.e., by using science).

- We must act reasonably (i.e., by using reason).

- The doctor removed the tumour surgically (i.e., by using surgery).

The above examples of instrumentality, however, do not necessarily reflect how various languages express instrumentality. Some languages, such as Latin, use a preposition and an ablative case ending: gladius $=a$ sword; cum gladio $=$ with $a$ sword . Hungarian uses suppletion, i.e., a morpheme completely changes its form when it comes in contact with another morpheme: a tyy $=$ the needle; a tyyvel = with the needle; az eke = the plough; az ekeevel = with the plough (Koutsoudas 1966)

These are surface forms, however, and $\mathrm{RC}$ is concerned with meaning. To indicate 'Instrumentality' in $\mathrm{RC}$, we can again use place-value. Expressions of instrumentality can be placed to the left of the verb, marked with a brace whose point faces leftwards.

\subsection{Conceptual and Cultural Requirements}

Placing instrumentality does not, however, solve all our problems. We have seen in Maun (2017) how the Australian aboriginal language Pintjantjatjara/Yankunytjatjara (hereafter, P/Y) uses varying verbs for to strike, according to the manner of striking, e.g., with a stick, with the hand, or with a spear (Goddard 1993). In that paper we also noted the necessity to 'tune' or 'focus' $\mathrm{RC}$ for the recipient of a message, i.e., make adjustments according to conceptual or cultural requirements. Thus if we are sending a message to a speaker of $\mathrm{P} / \mathrm{Y}$, it will be necessary to have a basic symbol for strike, applicable to languages such as English, French 
and German, but also extra instrumental icons meaning 'with a stick', 'with the hand' and 'with a spear', so that the $\mathrm{P} / \mathrm{Y}$ reader/writer can equate the characters with the verbs in $\mathrm{P} / \mathrm{Y}$.

Not all languages, however, are as simple in expressing instrumentality. In English, to lasso means to catch with a rope, a 'lasso' being a rope with a running noose. Such a definition will also suffice for French (prendre au lasso) or German (mit dem Lasso einfangen), and this could easily be illustrated for RC with a symbol for catch and an icon for cord, which exists as a lexical item in Basic English. However, Arizona Tewa makes no mention of a rope. Instead, two verbs are combined, -k'enu-, meaning 'to throw', and khwii-, meaning 'to tie'. (The dash represents a morpheme boundary in this, a polysynthetic language). Put together they produce $-k h w i i-$ k'enu-, 'tie throw', meaning to lasso (Kroskrity 2015). Temporarily, we can use '@' for 'to tie' and '** $\rightarrow$ ' for 'to throw' in RC. Since it is the throwing that is instrumental to the tying, the symbol for $k^{\prime}$ enu- $(* * \rightarrow)$ could be placed in Instrumental position in RC, i.e., on the left part of a symbol for the main verb, -khwii-, '@', with a brace symbol to show that this instrumental.

$$
* * \rightarrow\{@
$$

Thus, in accordance with Maun (2017), the glyph sent to a speaker of Arizona Tewa will be different from that sent to a speaker of English, French or German, but will be composed of basic symbols drawn from the RC lexicon. Similarly, as noted in the same paper, for German, for the verb 'to go', it is necessary to specify the manner of going, i.e., on foot, by car, by ship, by plane. For a German recipient of a message, the necessary symbol can be added to the left of that 
for the verb 'to go'. (This will be dome automatically by the RCD, once the language of the recipient is specified.)

\subsection{Manner}

Adverbials of manner are often clearly marked in some languages, e.g., with '-ly' in English, '-ment' in French or '-erweise' in German. Sometimes adverbial phrases using an adjective may replace a single adverb. Thus 'in a way', 'd'une façon ', 'auf einer

Weise', where the blank represents an adjective. Some languages, e.g., German, permit the use of the adjective to act as an adverb, e.g., 'Er spielt $g u t$ ' = 'He plays well.'

$\mathrm{RC}$ is concerned with function and meaning, not with form, and we can therefore use place-value for adverbials of manner, rather than marking them in a particular way. As the right-hand space of our glyph remains currently unoccupied, we can place adverbs of manner, or adverbial expressions of manner, in that gap.

Thus the adjuncts modifying the sense of the kernel of the sentence (S-V-C) are now identifiable by their position as a 'compass point' in a glyph: Time (N), Place (S), Manner (E) and Instrumentality (W). If an expression is found in one of these position, it is because it is expressing that particular function, e.g., North = time, not manner, place, etc.

Once the syntactic and semantic conventions for these positions have been learnt, the reader may read them in the order natural to his/her native language.

\subsection{Compound and Complex Sentences}

The clauses of compound sentences, i.e., with coordinated clauses 
('....and...'/ '...or...') will be joined by the ampersand (\&) or the logical symbol for 'or', namely ' $\mathrm{V}$ '.

The conjunction 'but' will be represented as 'not and...' ('...ᄀ\&...') (with the negative above the ampersand).

In RSVP on the RCD these secondary clauses will appear on the screen after the presentation of the clause to which they are to be attached. For present purposes, on the printed page, they will appear between clauses ('Clause X \& Clause Y'/ 'Clause X v Clause Y' / 'Clause $\mathrm{X} \neg \&$ Clause $\mathrm{Y}$ ').

In complex sentences, i.e., those with a subordinating conjunction, adverbial clauses of time (e.g., 'When I left...') will appear in the same position as temporal adverbials, i.e., above the main clause, signalled by an upward-pointing brace. We shall not deal here with adverbial clauses of place, but these will appear at the bottom of the glyph, as do adverbials of place, and these will be marked by a downward-pointing brace.

Relative clauses will be attached to the noun or pronoun to which they refer. Clauses referring to the subject or complement of the main clause will be joined to that subject by the symbol $\int$, which may be curved to fit the structure of the sentence.

\section{Part B}

\subsection{Basic Characters}

Our first nouns will be: person, man, woman and house. The first verb will be see.

These will be represented as follows, with explanatory notes in the 
102 A Tiny Language: Implementing a 'Real Character'

table to explain their construction or origin.

Table 1. Basic Characters

\begin{tabular}{|c|c|c|c|}
\hline No. & Item & Symbol & Notes \\
\hline 1 & person & & $\begin{array}{l}\text { From Chinese 'rén' (person). Semi-icon. } \\
\text { Curves suggest nature, not technology }\end{array}$ \\
\hline 2 & man & & $\begin{array}{l}\text { Semi-icon. Curves and straights. } \\
\text { The 'male' use of a straight for the arms }\end{array}$ \\
\hline 3 & woman & & $\begin{array}{l}\text { Semi-icon. Curves and straights. } \\
\text { The 'female' use of a curve for the arms }\end{array}$ \\
\hline 4 & house & & Icon. Straights. \\
\hline 5 & see & & $\begin{array}{l}\text { Adapted Haag Symbol - 'eye' (for Haag } \\
=\text { 'light') }\end{array}$ \\
\hline
\end{tabular}

With these elements it is possible to create at least the following sentence. Note that (a) the verb is tenseless, (b) there are no articles with the nouns, and (c) 'house' serves as the complement, not an adverbial of place. The nouns are taken to be indefinite.

man $\stackrel{2}{T}$ house

Notes:

(a) Markedness ( $a \mathrm{v}$. the) may be indicated by the use of superscripts. The definite article 'the', either refers anaphorically to a previously-mentioned referent, or is used as a marker of a referent which we assume to be known. Thus the opening sentence of a novel could read 'The man stood in the doorway, waiting'. We do not know who this man is, nor has been 
referred to before, but the definite article draws attention to him as a character to whom reference will be made in the future. In this, we can use superscripts. 'The $\operatorname{man}^{1}$ stood in the doorway, waiting. John Smith ${ }^{1}$ was over six feet tall.' We now know that the man is John Smith. Similarly, the two coreferences may be inverted: 'John Smith' stood in the doorway. The $\operatorname{man}^{1}$ was over six feet tall.' Our idea, drawn from his name, that John Smith is a man is confirmed. RC characters may be similarly indexed to show co-reference.

Not all languages use the definite v. indefinite distinction. Russian lacks definite articles.

(b) Note that 'house' is considered to be a complement, as the sentence 'Man see__ is incomplete without it. Similarly 'house' would be considered to be a complement in 'Man go ', rather than an adverbial ('to the house'), 'as 'Man go ' is incomplete, whereas 'Man go soon' is complete.

(c) Plurals, e.g., men, houses, may be marked with a multiplication sign (' $x$ ') underneath, cf. Blissymbolics.

(d) Proper nouns. Names such as 'John', 'Anne', 'Paris' or 'the Marquis of Queensberry' need not present a problem if we agree that, for any given message, names are defined in advance by their initial(s), and then enclosed in a 'cartouche' in the way that Egyptian names were represented in hieroglyphics. Thus, for the above names we would write J, A, $\mathrm{P}$ and $\mathrm{MQ}$, and enclose each in a cartouche.

\subsection{Tense}

To add tense, it is necessary to add a tense marker, except for the present which remains unmarked as the 'default' tense. In Haag's 
system, as noted in Section 2.6, 'past' is regarded as a shift of 'in front of' from the Spatial category into the Temporal category. Similarly, future is regarded as a shift of 'behind' into the Temporal category.

While adverbial adjuncts of Time are placed above the verb, as being additional to it, tense markers will form part of the verb itself, placed on its left. This means that if we have TENSE+VERB+ADVERBIAL, we do not get too much vertical stacking.

If an adverbial of phrase of time is used, e.g., 'yesterday', 'in two months' time', there is no need to mark the verb, as the tense symbol will be attached to the temporal adverbial, e.g., 'yesterday + PAST', 'in two days' time + FUTURE'.

Table 2. Tense Symbols

\begin{tabular}{|c|c|c|l|}
\hline No. & Item & Symbol & \multicolumn{1}{|c|}{ Notes } \\
\hline 6 & Past tense & $\boldsymbol{\bullet}$ & $\begin{array}{l}\text { Haag symbol 'in front of' with } \\
\text { 'time' brace }\end{array}$ \\
\hline 7 & Future tense & $\boldsymbol{|}$ & $\begin{array}{l}\text { Haag symbol 'behind' with 'time' } \\
\text { brace }\end{array}$ \\
\hline
\end{tabular}

Thus 'man saw house' is represented as:

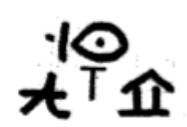

and 'man will see house' as:

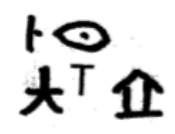




\subsection{Pronouns}

Having chosen the iconic Chinese character 'rén' as the most fundamental icon in RC (from which we have formed 'man' and 'woman'), we may now use this character to form pronouns. The left 'leg' of the character will serve for singular pronouns, and the right for plural forms. A straight or curved cross-bar may be added to indicate gender, if required, and number will be indicated by the appropriate number of dots or points above the cross-bar. Thus:

Table 3. Pronouns

\begin{tabular}{|c|c|c|c|}
\hline No. & Item & Symbol & Notes \\
\hline 8 & I & ) & First person singular. One point \\
\hline 9 & you (sg.) & $j$ & Second singular person. Two points \\
\hline 10 & he & 斗 & Third person singular, male. Three points \\
\hline 11 & she & $\nexists$ & $\begin{array}{l}\text { Third person singular, female. Three } \\
\text { points }\end{array}$ \\
\hline 12 & it & :21 & $\begin{array}{l}\text { Third person singular, neuter. Abstract } \\
\text { shape (see 'Thing' under expanded } \\
\text { lexicon). Three points }\end{array}$ \\
\hline 13 & we & $l^{\circ}$ & First person plural. One point \\
\hline 14 & you $(\mathrm{P} 1)$. & $\ell^{*}$ & $\begin{array}{l}\text { Second person plural*. Two points. } \\
\text { (*Some languages distinguish between } \\
\text { 'dual' and 'plural'.) }\end{array}$ \\
\hline 15 & they & 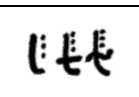 & $\begin{array}{l}\text { Third person plural. Three points. } \\
\text { Gender may be marked. }\end{array}$ \\
\hline
\end{tabular}

Used adjectivally, these pronouns may represent 'my', your', 'his', 'her', etc. When used in this way, they will be placed below the noun 
to which they refer.

\subsection{The Copula 'To Be'}

Essentially, the verb 'to be' is a copula, a linking element between the subject of a sentence and a complement or adverbial adjunct. The complement may take the form of a noun phrase (He is a policeman), an adjective or adjectival phrase (He is tall; He is very tall) or an adverbial phrase (He is in the garden). Other possibilities also exist.

Since 'to be' is extremely abstract, and therefore difficult to represent symbolically, we shall simply put a tense marker in the verb position on the T-bar. The absence of any other verb symbol thus indicates that the tense-marker applies to the verb 'to be'. Thus a sentence seen as 'He + PAST + tall' means 'He was tall'. Since a simple point '?' is used to represent 'now', this will represent the present tense of 'to be' when placed above the t-bar.

\subsection{Functional Symbols}

In order to have elements which will allow the creation of full sentences in RC, it is necessary to add functional symbols.

Table 4. Functional Symbols

\begin{tabular}{|c|c|c|l|}
\hline No. & Item & Symbol & \multicolumn{1}{|c|}{ Notes } \\
\hline A & now & $\bullet$ & Point from which other times derive \\
\hline B & in front of & $\bullet$ & Haag symbol \\
\hline C & behind & $\boldsymbol{1}$ & Haag symbol \\
\hline D & past & -1 & $\begin{array}{l}\text { Haag symbol 'in front of' in } \\
\text { 'Time' position }\end{array}$ \\
\hline
\end{tabular}




\begin{tabular}{|c|c|c|c|}
\hline $\mathrm{E}$ & future & $1 \cdot$ & $\begin{array}{l}\text { Haag symbol 'behind' in 'Time' } \\
\text { position }\end{array}$ \\
\hline $\mathrm{F}$ & open & .1 & Haag symbol \\
\hline G & closed & $\cdot 1 \cdot$ & Haag symbol \\
\hline $\mathrm{H}$ & [Cause] & [ & $\begin{array}{l}\text { [Replaces Haag triangle } \\
\text { representing his 'Force level III'] }\end{array}$ \\
\hline I & [Question] & ? & Speech act marker \\
\hline $\mathrm{J}$ & [Exclamation] & $!$ & Speech act marker \\
\hline $\mathrm{K}$ & [Command] & !! & Speech act marker \\
\hline $\mathrm{L}$ & [Modality] & $\lambda$ & $\begin{array}{l}\text { Haag's 'logos' category, marked } \\
\text { with Greek lambda symbol }\end{array}$ \\
\hline M & possible & $\lambda \cdots 1$ & $\begin{array}{l}\text { Speech act marker. Haag: 'Logos' } \\
\text { category with 'open' }\end{array}$ \\
\hline $\mathrm{N}$ & $\begin{array}{l}\text { impossible } \\
\text { ('not possible') }\end{array}$ & $\lambda \cdot 1 \cdot$ & $\begin{array}{l}\text { Speech act marker. Haag: 'Logos' } \\
\text { category with 'closed' }\end{array}$ \\
\hline $\mathrm{O}$ & probable & $|\lambda|$ & $\begin{array}{l}\text { Speech act marker. Haag: 'Logos' } \\
\text { category with 'near' }\end{array}$ \\
\hline $\mathrm{P}$ & because & $\because$ & Logic symbol \\
\hline $\mathrm{Q}$ & [Adverbial] & an. & Adverbial/adjunct marker \\
\hline $\mathrm{R}$ & $\begin{array}{c}\text { [Relative } \\
\text { clause marker } \\
\text { (subject)] }\end{array}$ & $\int$ & $\begin{array}{l}\text { May be reversed for clause } \\
\text { relating to object }\end{array}$ \\
\hline $\mathrm{S}$ & there is/are & $\exists$ & Logical existence symbol \\
\hline $\mathrm{T}$ & not & $\neg$ & $\begin{array}{l}\text { Logical negative, placed above } \\
\text { referent, e.g., verb }\end{array}$ \\
\hline $\mathrm{U}$ & and & $\&$ & Printer's ampersand \\
\hline $\mathrm{V}$ & or & $\mathbf{v}$ & Logical alternative symbol \\
\hline
\end{tabular}


108 A Tiny Language: Implementing a 'Real Character'

\begin{tabular}{|c|c|c|c|}
\hline W & but & $\overrightarrow{\boldsymbol{\&}}$ & 'but' = 'not and' \\
\hline $\mathrm{X}$ & with & () & $\begin{array}{l}\text { 'Together'. Encloses person or } \\
\text { thing. N.B. Not instrumental use, } \\
\text { e.g., 'with a knife' }\end{array}$ \\
\hline
\end{tabular}

\subsection{Expanding the Lexicon}

For the purposes of constructing the TL, let us add the following words. Most are taken directly from BE.

Nouns: $\quad$ town, place, thing, day, writing, letter ${ }^{1}$, car $^{2}$, aeroplane $^{2}$

Adjectives: quick, long, short

Verbs: $\quad$ go, come, hear, give, send [(i) physically,

(ii) electronically], do, leave ${ }^{3}$, arrive ${ }^{4}$

Prepositions: in, from, at, to

Conjunctions: and, or, but

Numbers: $\quad 1-59$

To these we shall add a small number of words which are not in BE, but are represented symbolically by Haag, or can be created.

${ }^{1}$ The Basic English Dictionary (1940) defines a letter as: 'Words in writing sent to a person'. This term will therefore serve both for a hard-copy text (letter) and for an electronic message (text, e-mail, $S M S$ ), each with the appropriate verb.

${ }^{2}$ These concepts do not exist in BE but must be represented by an icon.

${ }^{3} \mathrm{BE}$ : 'Go away (from)'. Haag has a ready-made symbol. 
${ }^{4} \mathrm{BE}$ : 'Come to'. Haag has a ready-made symbol.

Excluding the pronouns outlined above, this now gives us the following lexicon:

Table 5. Expanded Lexicon

\begin{tabular}{|c|c|c|c|}
\hline No. & Item & Symbol & Notes \\
\hline 1 & person & & Icon. $1 \& 2$ adapted \\
\hline 2 & man & & $\begin{array}{l}\text { Icon. Curves and straights. } \\
\text { 'Male' }\end{array}$ \\
\hline 3 & woman & & Icon. Curves. 'Female' \\
\hline 4 & house & & Icon. Straights \\
\hline 5 & town & & $\begin{array}{l}\text { Icon. Several houses. } \\
\text { Straights }\end{array}$ \\
\hline 6 & place & & $\begin{array}{l}\text { Symbol. 'Somewhere between } \\
\text { two points' }\end{array}$ \\
\hline 7 & thing & 口 & Symbol. Neutral shape \\
\hline 8 & day & O & $\begin{array}{l}\text { Symbol. Sun over horizon, } \\
\text { cf. Blissymbol }\end{array}$ \\
\hline 9 & writing & $\cos$ & Semi-icon. Neutral script \\
\hline 10 & letter/message & e3 / 圈 & Icon. Outline with text \\
\hline 11 & car & & Semi-icon. Neutral shape \\
\hline 12 & aeroplane & $\approx$ & Semi-icon. Neutral shape \\
\hline 13 & quick(ly) & $=$ & Cartoon zoom-lines \\
\hline 14 & long & 1 & Horizontal. End-lines apart \\
\hline 15 & short & 11 & Horizontal. End-lines close \\
\hline 16 & go & $\rightarrow$ & Haag Symbol \\
\hline
\end{tabular}


110 A Tiny Language: Implementing a 'Real Character'

\begin{tabular}{|c|c|c|c|}
\hline 17 & come & $\leftarrow$ & Haag Symbol \\
\hline 18 & see & $\infty$ & Haag Symbol \\
\hline 19 & hear & (3) & Haag Symbol \\
\hline 20 & give & $\mu$ & Open hand \\
\hline 21 & $\begin{array}{c}\text { send } \\
\text { (physically) }\end{array}$ & {$[\rightarrow$} & $\begin{array}{l}\text { 'Cause to go'. Haag symbol } \\
\text { with '[' instead of 'causative } \\
\text { triangle' }\end{array}$ \\
\hline 22 & $\begin{array}{c}\text { send } \\
\text { (electronically) }\end{array}$ & 引L & $\begin{array}{l}\text { 'Cause to go'. Haag symbol } \\
\text { with '[' and 'electricity' }\end{array}$ \\
\hline 23 & do & $\mu-\|$ & $\begin{array}{l}\mu \quad \text { (metaphorical) }+ \text { Haag } \\
\text { symbol: 'go through'? }\end{array}$ \\
\hline 24 & $\begin{array}{l}\text { depart, leave } \\
\text { (a place) }\end{array}$ & $H$. & $\begin{array}{l}\text { As verb - Haag symbol. BE: } \\
\text { 'go from' + 'place'. } \\
\text { As preposition = 'from' }\end{array}$ \\
\hline 25 & $\begin{array}{c}\text { arrive } \\
\text { (at a place) }\end{array}$ & $|\leftarrow / \rightarrow|$ & $\begin{array}{l}\text { BE: 'come/go' + end marker. } \\
\text { 'Place' is added to this Haag } \\
\text { symbol. As preposition = 'to' }\end{array}$ \\
\hline 26 & in & $1 \cdot 1$ & Haag symbol \\
\hline 27 & from & & $\begin{array}{l}\text { As verb - Haag symbol. BE: } \\
\text { 'go from' + 'place'. } \\
\text { As preposition = 'from' }\end{array}$ \\
\hline 28 & at & & $\begin{array}{l}\text { Indicates a given point in } \\
\text { space or time. }\end{array}$ \\
\hline 29 & to & & $\begin{array}{l}\text { BE: 'come/go' + end marker. } \\
\text { Haag symbol + 'place'. } \\
\text { As preposition = 'to' }\end{array}$ \\
\hline
\end{tabular}




\subsection{Combinatorics}

By combining various lexical and functional symbols, we may arrive at further vocabulary which will be necessary and useful. Thus:

Table 6. Number and Temporal Adverbials

\begin{tabular}{|c|c|c|l|}
\hline No. & Item & Symbol & \multicolumn{1}{|c|}{ Notes } \\
\hline 30 & numbers 1-59 & $1,2,3$, etc. & $1-59$ \\
\hline 31 & yesterday & $1 \frac{\mathbf{0}}{\mathbf{1}}$ & $\begin{array}{l}\text { Past symbol, } \\
\text { plus 'day' and '1' }\end{array}$ \\
\hline 32 & two days ago & $\mathbf{1} \frac{\mathbf{0}}{\mathbf{2}}$ & $\begin{array}{l}\text { Past symbol, } \\
\text { plus 'day' and '2' }\end{array}$ \\
\hline 33 & tomorrow & $\mathbf{1 \cdot \frac { \mathbf { 0 } } { \mathbf { 1 } }}$ & $\begin{array}{l}\text { Future symbol, } \\
\text { plus 'day' and '1' }\end{array}$ \\
\hline 34 & in two days & $\mathbf{1} \frac{\mathbf{0}}{\mathbf{2}}$ & $\begin{array}{l}\text { Future symbol, } \\
\text { plus 'day' and '2' }\end{array}$ \\
\hline 35 & week & $\frac{\mathbf{0}}{\mathbf{7}}$ & 'day' and '7' \\
\hline 36 & two weeks & $\mathbf{2 \frac { \mathbf { 0 } } { \mathbf { 7 } }}$ & '2' times 'day' and '7' \\
\hline 37 & month & $\mathbf{3 1} \frac{\mathbf{0}}{\mathbf{7}}$ & '31' times 'day' and '7' \\
\hline
\end{tabular}

This total set of words and expressions may appear to be a very small lexicon but once it is combined with markers indicating speech acts, tense, conjunctions, pronouns and functional markers there will be a considerable number of symbols and an increasingly large possibility of sentence and message-types. 
112 A Tiny Language: Implementing a 'Real Character'

\subsection{Creating Sentences}

We can now create some sample sentences, whose $\mathrm{RC}$ versions may be seen on the opposite page.
a) Does a man see a house?
b) The man did not see the house.
c) Did the man not see a woman?
d) I sent a message to you (sg.)
e) Did you (sg.) send a message to me?
f) It's possible (that) the man sent a short message to you (sg.).
g) Tomorrow I shall go to (the) town.
h) Two days ago, I drove to (the) town.
i) In three weeks' time, I shall fly to Paris. [Paris $=\mathrm{P}$ in a cartouche]
j) I shall leave Berlin at 15.45. [Berlin $=\mathrm{B}$ in a cartouche] 
a)

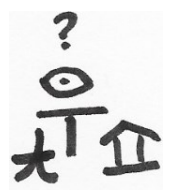

c)

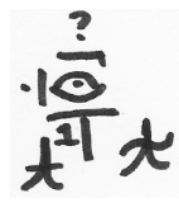

e)

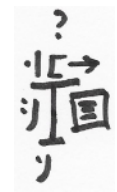

g) $\frac{1 \cdot \frac{0}{2}}{\sum_{-1}^{\frac{1}{2}}}$

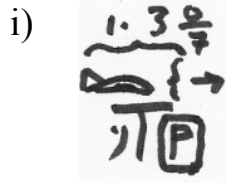

b)

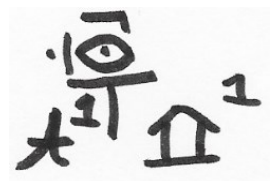

d) $\frac{1[}{\sqrt{1}}$

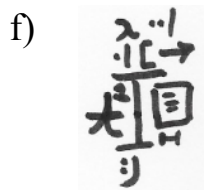

h) $\frac{1 \frac{0}{2}}{\text { ग1 } \rightarrow 1}$

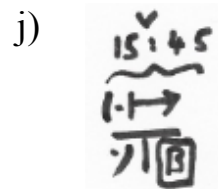


k) I shall arrive in Paris and I shall quickly drive to my house.

1) I shall see you (pl.) there [in that place].

m) I did not go (drive) to the town.

n) There are two men in the house! I heard them.

o) I did not see them.

p) The men who were in the house have gone. Is it possible that they saw you (sg.)?

q) No. It's impossible. I was behind the house.

k) $\quad 1 \cdot \rightarrow$

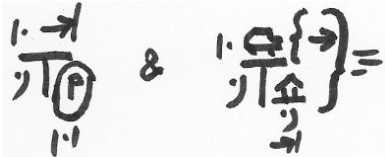

m)

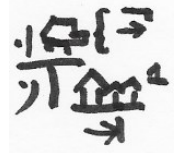

n)

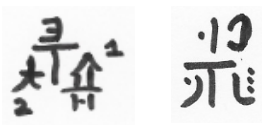

1)

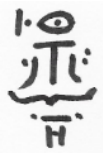

p)
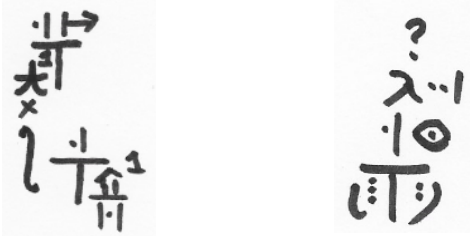

q) ᄀ

$$
\text { 泫 } \quad \frac{1}{21 \frac{\pi}{1}}
$$

o) $\frac{.10}{110}$

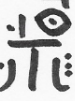




\subsection{Exercises}

A. What do sentences 1-5 (below) mean?

1)

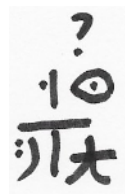

3)

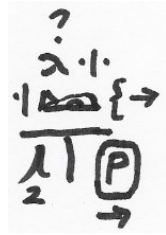

5)

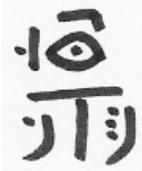

2)

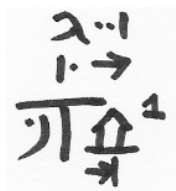

4)

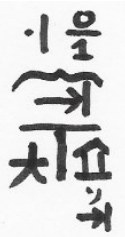

霫

B. How would you write...?

1. I saw an aeroplane.

2. Did you see my house?

3. John [J in cartouche] didn't arrive in Berlin at 17.56 because he drove and didn't fly.

4. Is it possible that you'll be in Paris?

5. John sent me a long letter because he was in Paris.

See page 124 for answers. 


\subsection{Form and Appearance}

Is the style and appearance of the characters thus far proposed in order to represent concepts both consistent and visually pleasing enough to assure cognitive consonance and prevent cognitive dissonance in the reader, or is some consolidation and stylisation necessary? Cognitive consonance is a calm psychological state produced when images, notions, beliefs etc. are in harmony with each other. Cognitive dissonance, on the other hand, is a variety of psychological stress caused by contrary images, notions, beliefs, etc. which will not match with each other (Pinker 1997).

In this series of articles, a number of illustrations have been used as examples. These have variously been drawn from:

- Images on the Internet

- Symbols from various computer fonts

- Symbols appearing on the computer keyboard

This eclectic variety of print-images is unlike normal writing systems for natural languages. Cultures and their languages are usually characterised by a highly consistent writing-system. Thus, Chinese by its dense, stroke-driven characters, Japanese by kanji and kana (hiragana and katakana), Arabic by its distinctive curling calligraphics, Hebrew by its squarish letters (known as 'square Hebrew') and its diacritical marks, and some Indian languages by their letters written below a line known as a 'power'. Later ancient Egyptian scripts such as hieratic and demotic were characterised by flowing adaptations of early hieroglyphs, a subject to which we shall return later.

English and many other languages today use single letters linked 
to form words, these letters sharing common characteristics known as a 'type-face' or 'font'. These characteristics include the ratio of height to width, the general thickness of the strokes, the variety of stroke types within a letter (e.g., thick for the stem v. thin for the side-strokes known as 'legs' and 'arms'), the use of serifs (ornamental additions at the extremities of strokes) or the lack thereof, associations caused by use (e.g., Times New Roman for serious articles, Comic Sans for light-hearted communications) and, sometimes, associations caused by similarity to foreign scripts, e.g., a Chinese restaurant named 'Cantonese House' whose sign has English words written in Chinese-like characters. It is usual for such a message to be written in a consistent font.

What every font has, however, is internal consistency. Indeed it is this very consistency which allows a font to be labelled with a given name. A font is, essentially, a family of letters, with family resemblances predominant among its members. When such resemblances are lacking in a printed message, the effect can be one of cognitive dissonance. Jackendoff (1993: 181-182) notes 'For a very rough approximation - which is all we'll need here-it seems that elements of the visual vocabulary, such as letters of the alphabet, are stored in the brain in terms of sets of criteria...[O]ur unconscious criteria for elements of the visual vocabulary tolerate a certain amount of deviation but not too much. ...We don't tolerate marginal members of a category without some associated cognitive stress ... That is, ideal configurations in some sense make us happier than marginal ones.'

In other words, if we were to mix various type-face within a given word, the criteria for cognitive consonance would be absent. Try this: consternating. Here the mind has the extra burden of unravelling changes in size, shape, orientation, etc. No such stress would be caused if the word were written in a consistent font (i.e., as 'consternating'). Dondis (1973) notes how the concept of 'stress' itself can be illustrated by a constantly-changing arrangement of 
shapes.

At present, the visual system of RC lacks the consistency of a font, being drawn from a variety of sources. Furthermore, it lacks a style, a distinguishing feature or set of features, which will impart an identity to all its elements at once, thus avoiding any possible cognitive diossonance on the part of the reader. In future development of RC, such a style will have to be accessible and 'welcoming', i.e., it will not, by its very form, reject the reader and create affective reactions which fail to enable that reader to penetrate the text to create meaning (Maun 2005, Maun \& Myhill 2005). Ultimately a full lexicon for RC will need to be created, probably under the guiding hands of linguists, psychologists and artists. Such a lexicon should be written in a script which is aesthetically attractive, without the dangers of its form taking precedence over meaning, as is known to occur among some foreign students of Chinese and Japanese (DeFrancis 1984, Unger 2004).

\subsection{From Icon to Script}

$\mathrm{RC}$ consists mainly of icons and symbols, with indices being a possible element. In some of the previous papers, icons have been obtained from the Internet, e.g., 'child' and 'watch' (Maun 2015), and some icon-like symbols, e.g., 'see' have also been taken from the Web. These particular choices are, in the end, arbitrary, however. Another picture of a watch or a child could have been used. A symbol other than an eye could have been used for the verb 'see'. The present writer had a totally free choice.

Distinction of sound is, in the best writing systems, marked by distinction of letters, and both the reader and the writer must be able to distinguish each letter from its fellows. Similarly with meaning in 
RC. A laissez-faire approach to writing is not possible. There must be a degree of conventionalisation to which interlocutors conform when writing and reading. Future users of RC will, then, have to accept conventionalised, prescribed icons and symbols, although there will be slight variations because of the choice of language for the destinee. Thus, as pointed out in Maun (2017), there will be variations in the icons for 'cow' and 'bread', because those things look different in different parts of the world. Nevertheless, there will be limits, and users will have to accept an icon chosen as being broadly stereotypical.

Once a 'style' has been adopted (see above, Section 3.10) there will be a degree of uniformity among the characters of RC, cf. Korean Hangul script which is limited in strokes, open in style and adjustable so that all characters are the same size (Coulmas 1996). Characters will be stored in the memory of the RCD and, when messages are composed, will order themselves appropriately ( $\mathrm{S}-\mathrm{V}-\mathrm{C}$, etc.), adjusting themselves to fit the screen size and with a 'look' that is aesthetically pleasing and causes no cognitive dissonance.

The aim in developing $\mathrm{RC}$ thus far has always been that of a digitally available system of communication. There is no reason however, why RC, once fully developed, should not be transmissible by other media, nor why it should not be adaptable to other means of production. In a situation in which speakers of two mutually unintelligible languages are seated next to each other, there should be no barrier to their communicating with each other using hand-written notes on paper. This might be necessary if no RCD device were available, if no Internet signal could be reached, or if electronic communication were interrupted by atmospheric conditions (solar flare, Carrington Event, etc.)

Thus a possible future development of RC might be a script-form, 
more flowing and linked than the currently proposed symbols, and which might be equally recognisable, though somewhat different in appearance, cf. current printed script $v$. hand-writing. The history of 'hard-copy language' shows multiple examples of the way in which styles of writing have developed through various stages, e.g., Egyptian hieroglyphics via hieratic into demotic, Akkadian cuneiform into written Sumerian, Chinese idographs into conventionalised characters (Gelb 1963, Pope 1975, Coulmas 1996, Robinson 2007).

Such a development of RC might require a body or authority to oversee it. Therein, however, lies one of the great weaknesses of languages that may be described as 'artificial'. Not being subject to the natural laws of linguistic development, their evolution may be dependent on the arbitrary opinions or decisions of individuals or committees, with which other people may not agree. Esperanto underwent a tectonic shift when a breakaway group of Esperantists developed Ido (Couturat 1903, Pei 1958), and Charles Bliss struggled to keep control of the development of Blissymbolics (Helfmann 1981). If RC were to develop from a digital form to a manual version, then its future would have to monitored in some way, lest the near-universality of its symbols were reduced or constrained, and mutually incomprehensible 'dialects' were to develop.

But that is for the future....

\section{Conclusion}

At present, sufficient progress has been made in the theory of $\mathrm{RC}$ for this system to show a firm foundation and the first inklings of a practical digital form. Incorporating the work of the early 'language 
projectors', the work of Karl Haag, Morris Swadesh and others, there is no reason why 'Real Character' should not, one day, be numbered among the more successful attempts to create communication between people who speak mutually unintelligible languages. It may take many years to develop both the RC script and the RCD. Once this is done, we may see perhaps $\mathrm{RC}$ as commonly as we see computer icons, logos, 'emojis' or scripts such as Pitman shorthand or Braille. Time will tell.

\section{References}

Coulmas, F. 1996. The Blackwell Encyclopedia of Writing Systems. Oxford: Blackwell Publishers.

Couturat, L. 1903. Histoire de la langue universelle. Paris: Hachette. Kessinger reprint on demand.

Croft, W. \& D. Cruse. 2004. Cognitive Linguistics. Cambridge: CUP. Crystal, D. 1987. The Cambridge Encyclopedia of Language. Cambridge: CUP.

DeFrancis, J. 1984. The Chinese Language. Fact and Fantasy. Honolulu, HI: University of Hawaii Press.

Deutscher, G. 2010. Through the Language Glass. How Words Colour Your World. London: Heinemann.

Dondis, D. 1973. A Primer of Visual Literacy. Cambridge, MA \& London: MIT Press.

Everitt, D. 2012. Language. The Cultural Tool. London: Profile Books. Frutiger, A. 1989. Signs and Symbols. Their Design and Meaning. Translated from the German Der Mensch und seine Zeichen, 1978. London: Studio Editions.

Gelb, I. 1963. A Study of Writing. Chicago, IL: University of Chicago 
Press.

Goddard, C. 1993. A Learner's Guide to Pintjantjatjara/Yankunytjatjara. Alice Springs: IAD Press.

Goddard, C. 2010. NSM. Available at URL $<$ http://www.griffith.edu.au/humanities-languages/schoollanguages-linguistics/research/natural-semantic-metalanguagehomepage $>$.

Haag, K. 1902. Versuch einer graphischen Sprache auf logischer Grundlage. (Towards a Logically-Based Graphical Language.) Stuttgart: W. Kohlhammer.

Haag, K. 1935. Das Denkgerüst der Sprache. Die Bestandteile des Denkens als die Grundlagen des Sprachbaus. (The Cognitive Basis of Language. The Elements of Thought as the Foundations of the Structure of Language.) Heidelberg: Carl Winters Universitätsbuchhandlung.

Helfmann, E. 1981. Blissymbolics. Speaking Without Speech. New York: Elsevier/Nelson Books.

Jackendoff, R. 1993. Patterns in the Mind. Language and Human Nature. New York \& London: Harvester-Wheatsheaf.

Koutsoudas, A. 1966. Writing Transformational Grammars: An Introduction. New York: McGraw-Hill Book Company.

Kroskrity, P. 2015. Designing a Dictionary for an Endangered Language Community: Lexicographical Deliberations, Language Ideological Clarifications. Language Documentation \& Conservation 9, 140-157.

Maun, I. 2005. A New Order: Reading Functionally Graded Texts in French. Francophonie 31.1, 8-15.

Maun, I. 2013. Towards a 'Real Character' for the Computer Age. Journal of Universal Language 14.1, 143-184.

Maun, I. 2015. 'Real Character'. Towards a Lexicon. Journal of 
Universal Language 16.1, 87-130.

Maun, I. 2016. Karl Haag, Modern Linguistics and 'Real Character'. Journal of Universal Language 17.2, 53-110.

Maun, I. 2017. 'Real Character': A New Focus. Journal of Universal Language 18.2, 105-147.

Maun, I. \& D. Myhill. 2005. Text as Design, Writers as Designers. English in Education 39.2, 5-21.

Ogden, C. 1930. Basic English. Cambridge: The Orthological Institute. Ogden, C. 1944. The Basic Words. London: Kegan Paul, Trench, Trubner \& Co.

Ogden, C. (ed.) 1940. The General Basic English Dictionary. London: Evans Bros.

Öquist, G. \& M. Goldstein. 2002. Towards an Improved Readability on Mobile Devices: Evaluating Adaptive Rapid Serial Visualisation. In F. Paternò (ed.), Human Computer Interaction with Mobile Devices: Proceedings of $4^{\text {th }}$ International Symposium (Mobile HCI 2012) 225-240. Berlin: Springer-Verlag. Pei, M. 1958. One Language for the World. New York: The DevinAdair Company.

Pinker, S. 1997. How the Mind Works. Harmondsworth: Penguin.

Pope, M. 1975. The Story of Decipherment. London: Thames \& Hudson. Robinson, A. 2007. The Story of Writing. Alphabets, Hieroglyphs \& Pictograms. $2^{\text {nd }}$ edition. London: Thames \& Hudson.

Swadesh, M. 1950. Salish Internal Relationships. International Journal of American Linguistics 16, 157-167.

Swadesh, M. 1971. The Origin and Diversification of Language. Edited post mortem by Joel Sherzer. Chicago, IL: Aldine.

Unger, J. 2004. Ideogram. Chinese Characters and the Myth of Disembodied Meaning. Honolulu, HI: University of Hawaii Press. 
124 A Tiny Language: Implementing a 'Real Character'

\section{Answers to Exercises}

Exercise A

1. Did you (sg.) see a man?

2. It is possible that I shall go to the house.

3. Is it not possible (that) two people flew to Paris?

4. A man arrived at my house yesterday.

5. I did not see him because I was in Berlin.

Exercise B

1.

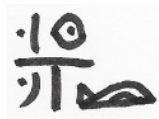

2.

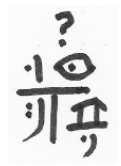

3. $17: 56$
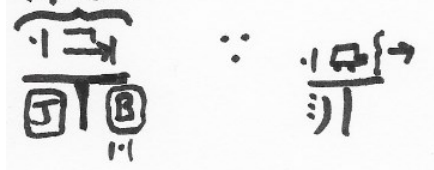

\& $\quad$ 난

4.

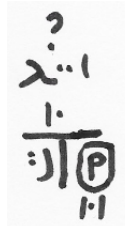

5.
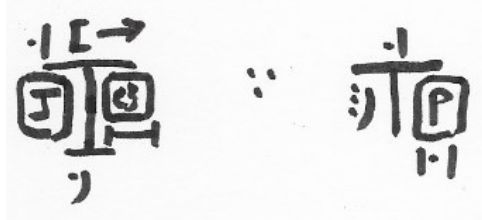